\title{
Associations between fatigue attributions and fatigue, health, and psychosocial work characteristics: a study among employees visiting a physician with fatigue
}

\author{
H Andrea, IJ Kant, A J H M Beurskens, J F M Metsemakers, C P van Schayck
}

Occup Environ Med 2003;60(Suppl I):i99-i 104

See end of article for authors' affiliations

Correspondence to: Drs H Andrea, Department of General Practice, Maastricht University, PO Box 616, 6200 MD Maastricht, Netherlands: Helene.Andrea@ HAG.unimaas.n

Accepted 11 October 2002

\begin{abstract}
Aims: To study associations between characteristics of employees active at work and making a fatigue related visit to the general practitioner (GP) or occupational physician (OP) in terms of fatigue, physical health problems, mental health problems, psychosocial work characteristics, and attributions of their fatigue complaints.

Methods: Self report questionnaires from the Maastricht Cohort Study Fatigue at Work were used to measure fatigue (Checklist Individual Strength, Maslach Burnout Inventory-General Survey), physical health problems (chronic illness), mental health problems (Hospital Anxiety and Depression Scale), psychosocial work characteristics (Job Content Questionnaire), and fatigue attributions (somatic, psychological, none) in employees who made a fatigue related visit to the GP or OP over a six month period. Results: In employees visiting only the GP, fatigue was an important reason to visit in one of seven $(13.9 \%)$ employees. These fatigue related visits were in particular associated with high fatigue levels and mental health problems. A psychological fatigue attribution was reported by $41.8 \%$, a somatic fatigue attribution by $44.0 \%$. On a multivariate level, mental health problems showed the strongest association with psychological fatigue attributions, over and beyond fatigue itself. No associations were found between fatigue attributions and psychosocial work characteristics. Attributional patterns appeared to be different between visitors of the GP and the OP.

Conclusions: Fatigue is a common reason among employees to consult a GP. Asking employees for their own fatigue attributions in terms of somatic or psychological causes may be useful for the GP - and possibly also the OP_to gather information about underlying health problems in employees active at work and making a fatigue related visit.
\end{abstract}

$\mathrm{F}$ atigue is a common complaint in both the general ${ }^{1-3}$ and the working population. ${ }^{4}$ Fatigue that becomes prolonged may lead to sick leave and work disability, ${ }^{5}$ which can have serious consequences for both employers (for example, costs due to loss of productivity) and employees (for example, reduced income, social isolation), and costs of care provided by family members or friends of the fatigued patient (for example, household activities). ${ }^{6}$ In the general population, fatigue is found to be associated with not only a broad range of somatic conditions, ${ }^{7}$ but also with mental health problems, especially in the form of depression and/or anxiety. ${ }^{89}$ The presence of somatic conditions and anxiety and/or depression can also be directly associated with one another. ${ }^{10-12}$ This complex relationship also applies to the working population. Psychosocial work characteristics including job demands, decision latitude, and social support at work are found to be associated with the presence of fatigue, chronic illness, and mental health problems. ${ }^{13-15}$ Hence, fatigue in the working population can be intertwined with a broad range of other problems in the field of work and health.

In the Dutch health care system and in several other European countries, general practitioners (GPs) are gatekeepers for the general population, including the working population.

\section{Main messages}

- In a working population a high proportion of patients have consulted their GP for fatigue as a presenting or supporting symptom in the previous six months.

- In the working population patients of the GP seem to be fairly accurate in their attributions of fatigue being caused by a psychological or physical problem.

- In the working population fatigue attributions were not associated with psychosocial work characteristics.
Therefore, GPs are likely the first to be involved in the diagnostic process concerning employed fatigued patients. GPs are often confronted with patients in relation to fatigue. Percentages of fatigue in the general practice population range from $5 \%$ to $45 \%$, with fatigue measured either as a presenting complaint or as a "supporting" symptom-that is, one of the possible symptoms of a clinical condition. ${ }^{16}$ To date, there are no specific data for the working population. However, since the working population comprises a substantial part of the general population (approximately 65\% in the Netherlands) it is assumed that GPs are also often confronted with employees with fatigue complaints. Furthermore, it is not only GPs that are likely to be regularly confronted with these patients. As in many other countries, Dutch employees also have the opportunity to visit their occupational physician (OP). From 1998, all Dutch companies and organisations have provided access to an OP for their employees. The task of the OP is not only reintegration of employees after sick leave, but also support of employees active at work but experiencing problems in

\section{Policy implications}

- Asking patients about their fatigue attributions might help physicians gaining insight in underlying health problems for fatigue.

- OPs were more likely than GPs to be confronted with employees with a psychological fatigue attribution, in employees making a fatigue related visit.

Abbreviations: CIS, Checklist Individual Strength; GP, general practitioner; HAD, Hospital Anxiety and Depression Scale; JCQ, Job Content Questionnaire; MBI-GS, Maslach Burnout Inventory-General Survey; OP, occupational physician 
their working situation. ${ }^{17}$ When employees consult their OP in relation to work, fatigue may be one of the complaints.

When employees make a fatigue related visit, the diagnostic process and support and/or treatment by the physician may be hindered by the intertwined relation between fatigue, health, and work problems. Firstly, a fatigue related visit may not only be related to fatigue severity, but may also reflect different underlying health and work problems. Secondly, patients' own opinions about the cause of their fatigue complaints and subsequent fatigue attributions (for example, somatic, psychological) may be affected and diffused by this intertwined relationship. The latter may not only hinder a correct diagnosis but may also affect patient compliance during treatment.

Little is known about how employed patients attribute their fatigue complaints. In this study, we examined the associations between fatigue attributions, fatigue level, physical health problems (chronic illness), mental health problems (anxiety and/or depression), and psychosocial work characteristics (job demands, decision latitude, social support). The study was conducted within the Maastricht cohort study, a large epidemiological study on fatigue at work. Within this cohort, we focused on employees who were active at work (not on sick leave) and who made a fatigue related visit to a physician (GP, OP). Within this subcohort, our main research questions were:

- Do employees who have consulted their GP with fatigue as a presenting or a supporting symptom differ from employees who did not consult their GP with fatigue as a presenting or a supporting symptom, in terms of fatigue level, health problems, and psychosocial work characteristics?

- What are the associations between employees' own fatigue attributions (somatic, psychological) and fatigue, health problems, and psychosocial work characteristics?

- Do these attributional patterns differ between employees who visited a GP and employees who visited an OP?

\section{METHODS \\ Study population}

Between May 1998 and January 2001, a large scale epidemiological cohort study addressing a broad range of work related, non-work related, and individual factors possibly associated with fatigue, was conducted in the Netherlands. This Maastricht Cohort Study of Fatigue at Work surveyed a population of over 12000 employees at baseline from 45 different companies and organisations using self report questionnaires that were sent to the cohort participants every four months. Full details of design of the cohort study, baseline characteristics of the study population, and a non-response analysis have been described elsewhere. ${ }^{48}$ Data about having visited the GP and/or OP and fatigue attributions were gathered in the Maastricht Cohort Questionnaire of January $2001(\mathrm{n}=7482)$.

Our study population consisted of employees who were active at work and who made a fatigue related visit to the GP or the OP only. This population was selected in several steps. First, we excluded those cohort participants not actively at work $(\mathrm{n}=574)$ or with missing values regarding working status $(n=80)$ or having visited the GP and OP $(n=36)$. Employees who visited the GP only were asked whether fatigue was in at least one visit an important reason to visit, with "yes" or "no" as the reply options. Employees who answered "yes" were defined as employees who made a fatigue related visit to the GP. For these employees, their own attributions of fatigue complaints were checked using the question "according to you, what was the cause of your fatigue?", with "somatic", "psychological", or "don't know" as the reply options. The same sequence of questions was asked to indicate attributions of employees who made a fatigue related visit to only the OP.

\section{Measurements}

Fatigue

To determine the level of fatigue in the cohort participants, the self report Checklist Individual Strength (CIS) was used. ${ }^{19} 20$ This multidimensional questionnaire consists of 20 items covering several aspects fitting the concept of prolonged fatigue (for example, lack of concentration, fatigue severity). Subjects are instructed to indicate how they felt during the past two weeks. The response to each statement is scored on a seven point Likert scale, varying from "yes, that is true" to "no, that is not true". A higher CIS total score (range 20-140) indicates a higher level of fatigue. Cronbach's alpha for the total CIS score was 0.96 . To be able to determine the prevalence of fatigue in employees, a cutoff point for fatigue for use in the working population was developed..$^{21}$ Using this cutoff point, employees scoring $>76$ are designated as probable fatigue cases, with a fatigue level that can be indicated as putting the employee "at risk" for sick leave or work disability.

Work related fatigue was assessed with the Dutch version of the Maslach Burnout Inventory-General Survey (MBIGS). ${ }^{22}{ }^{23}$ The MBI-GS consists of three subscales: exhaustion (five items), cynicism (five items), and professional efficacy (five items). All items are scored on a seven point frequency scale, ranging from " 0 " (never) to " 6 " (daily). High scores on exhaustion and cynicism, and low scores on professional efficacy are indicative for burnout or work related fatigue. According to the Dutch MBI-GS manual, subjects scoring in the highest quartile of exhaustion and either the highest quartile of cynicism or lowest quartile of professional efficacy are defined as burnout cases. ${ }^{23}$

\section{Physical health problems}

Physical health problems were measured by the presence of at least one chronic illness. Cohort participants reported whether they had one or more of an extensive list of 19 conditions with a somatic character as measured in May 2000, including heart problems, stroke, liver problems, diabetes, cancer, respiratory disorders, metabolic disorders, skin disorders, musculoskeletal problems, and severe consequences of an accident (for example, fractures).

\section{Mental health problems}

The Hospital Anxiety and Depression Scale (HAD) was used to measure the presence of anxiety and/or depression. The HAD is a self report questionnaire, establishing the presence and severity of both anxiety and depression, providing a separate score for each. ${ }^{24}$ Both the HAD anxiety and the HAD depression subscales consist of seven items, with a range from 0 to 21 . Cronbach's alpha was 0.84 for HAD depression and 0.83 for HAD anxiety. Employees were defined as being a probable case of having a mental health problem in the form of anxiety and/or depression when they scored 11 or higher on the HAD anxiety and/or the HAD depression subscale, ${ }^{25}$ which is suggested to be a proper threshold score for use in a general practice population. ${ }^{26}$

\section{Psychosocial work characteristics}

The subscales job demands (five items), decision latitude (also referred to as job control; nine items), and social support (eight items) of the Dutch version of the Job Content Questionnaire (JCQ) were measured in May 2000 and indicate scores on psychosocial work characteristics, reflecting the perception of employees of their psychosocial work environment. ${ }^{27}{ }^{28}$ The responses on all items are scored on a four point Likert scale, varying from "strongly disagree" to "strongly agree". After scale construction, the scale ranges for job demands, decision latitude, and social support were 12-48, 24-96, and 8-32 and Cronbach's alphas were 0.70, 0.81, and 0.81 , respectively. Job strain, referring to the combination of 
high scores on job demands and a low score on decision latitude (and optionally also a low score on social support) is particularly suggested to be associated with negative health effects. ${ }^{29}{ }^{30}$ Employees scoring in the highest tertile of job demands and either in the lowest tertile of decision latitude or the lowest tertile of social support were defined as experiencing job strain.

\section{Sociodemographics}

Sociodemographic variables gender, age, educational level, and living situation (living alone: yes or no) were measured in the baseline questionnaire (May 1998) and were also taken into consideration in this study.

\section{Statistical analyses}

All data analyses were two tailed and were performed using SPSS version 10.0 for Windows. Employees with incomplete data were excluded from the analysis. Fatigue, health and psychosocial work characteristics of employees who made a fatigue related visit to the GP only were compared to the characteristics of employees who made a non-fatigue related visit to the GP only, using Fisher's exact test for the dichotomous variables and $t$ tests for the continuous variables. For employees who made a fatigue related visit to the GP only, the relation between their fatigue attributions and their fatigue, health, and psychosocial work characteristics were measured using ANOVA tests for the continuous variables and $\chi^{2}$ tests for the dichotomous variables. In the ANOVA analyses, Hochberg's GT2 was used as the post hoc multiple comparison procedure, as the sample sizes of the three attribution groups were not equal. ${ }^{31}$ In the univariate $\chi^{2}$ analyses comparing fatigue attributions, adjustment for multiple testing took place by taking into account differences of at least $\mathrm{p}<0.01$ only. Next, a multinomial logistic regression analysis was conducted to examine whether a model including being a probable fatigue case, reporting at least one chronic illness, being a probable mental health problem case, and experiencing job strain was associated to reporting a somatic, psychological, or no attribution, adjusted for sociodemographics. As a last step, fatigue attributions of employees having visited only the OP were compared to fatigue attributions of employees having visited only the GP.

\section{RESULTS}

Fatigue, health, and psychosocial work characteristics of employees who made a fatigue related visit to the GP

Of the employees at work who visited only the GP during the past six months, 97.6\% $(\mathrm{n}=2318)$ indicated whether their visit to the GP was fatigue related or not. Approximately one in seven of these employees (13.9\%) made a fatigue related visit. Table 1 compares their characteristics to the employees who made a non-fatigue related visit to the GP only.

The results indicate that employees who made a fatigue related visit not only had a higher level of fatigue, but also had a higher level of anxiety and depression. Furthermore, a higher percentage of employees who made a fatigue related visit to the GP only, reported at least one chronic illness. A more negative perception of the work environment was also present, but only with a modest clinical significance (for all three psychosocial work characteristics, the difference was less than $5 \%$ ). No differences were found regarding sociodemographic variables.

\section{Associations between fatigue attributions and fatigue, health, and psychosocial work characteristics}

As table 2 shows, $44.0 \%$ of employees who made a fatigue related visit to only the GP reported psychological fatigue attributions, $41.8 \%$ reported somatic attributions, and 14.2\% reported "don't know" as fatigue attributions.
Employees with a fatigue psychological attribution were found to have a higher level of fatigue, anxiety, and depression than employees with a somatic attribution, and a higher percentage of probable cases of work related fatigue were present among them. No differences were found regarding being a probable fatigue case four months ago, having at least one chronic illness, and sociodemographics.

Table 3 shows that being a probable fatigue case $(56.0 \%)$ and being a probable mental health problem case versus not being a probable fatigue case and not being a probable mental health problem case respectively, were associated to the attributional fatigue pattern in employees who made a fatigue related visit to only the GP.

A higher percentage of employees being a probable fatigue case or employees being a probable mental health problem case reported a psychological attribution $(51.4 \%$ versus $36.4 \%$ and $58.8 \%$ versus $37.8 \%$, respectively), while a higher percentage of employees not being a probable fatigue or mental health problem case reported a somatic attribution $(52.9 \%$ versus $31.3 \%$ and $50.6 \%$ versus $21.3 \%$, respectively). To a lesser extent, reporting at least one chronic illness $(34.2 \%)$ versus reporting no chronic illness or experiencing job strain $(20.5 \%)$ versus not reporting job strain also seemed to match with reporting a somatic or a psychological fatigue attribution respectively, but these associations were not significant.

Next, a multinomial logistic regression analysis was conducted to examine whether a model consisting of being a probable fatigue case, reporting at least one chronic illness, being a probable mental health problem case, or experiencing job strain was associated with the fatigue attributions of employees who made a fatigue related visit to only the GP, adjusted for sociodemographics. Since table 3 indicated a significant association between being a probable fatigue or mental health problem case and a psychological fatigue attribution, we chose the psychological fatigue attribution group as the reference group. Consequently, employees with a psychological fatigue attribution were compared to those with a somatic attribution and to those with no attribution.

Table 1 Characteristics of employees who made a non-fatigue related visit or a fatigue related visit to the GP only ( $n=2318)$

\begin{tabular}{lll}
\hline & \multicolumn{2}{l}{ Frequency, mean (SD) } \\
\cline { 2 - 3 } & $\begin{array}{l}\text { Non-fatigue related } \\
\text { visit (86.1\%) }\end{array}$ & $\begin{array}{l}\text { Fatigue related } \\
\text { visit (13.9\%) }\end{array}$ \\
\hline Fatigue & & \\
CIS total score*** & $55.5(23.6)$ & $79.1(25.0)$ \\
CIS case*** & $21.4 \%$ & $56.0 \%$ \\
$\begin{array}{c}\text { MBI-GS case*** } \\
\text { Somatic health problems }\end{array}$ & $14.3 \%$ & $38.2 \%$ \\
$\geqslant 1$ Chronic illness** & $24.8 \%$ & $34.2 \%$ \\
Mental health problems & & \\
HAD anxiety*** & $4.8(3.4)$ & $8.0(3.8)$ \\
HAD depression*** & $3.6(3.5)$ & $6.9(4.4)$ \\
HAD case*** & $9.7 \%$ & $32.8 \%$ \\
Psychosocial work characteristics (JCQ total score per subscale) \\
Job demand*** & $31.9(5.4)$ & $33.6(5.6)$ \\
Decision latitude** & $72.4(10.0)$ & $70.5(11.7)$ \\
Social support*** & $22.4(3.0)$ & $21.4(3.5)$ \\
Job strain* & $15.2 \%$ & $20.5 \%$ \\
Sociodemographics & & \\
Age (years) & $41.6(8.5)$ & $41.7(8.2)$ \\
Gender (\% male) & $67.8 \%$ & $65.4 \%$ \\
Low educational level & $15.3 \%$ & $15.8 \%$ \\
Living alone & $8.7 \%$ & $10.6 \%$ \\
\hline
\end{tabular}

$\mathrm{CIS}$, Checklist Individual Strength; CIS case, probable fatigue case; MBI-GS, Maslach Burnout Inventory-General Survey; MBI-GS case, probable work related fatigue case; HAD, Hospital Anxiety and Depression Scale; HAD case, probable mental health problem case; $J C Q$, Job Content Questionnaire.

$t$ test/Fisher's exact test, ${ }^{*} p<0.05,{ }^{* *} p<0.01,{ }^{* *}{ }^{*} p<0.001$ 
Table 2 Fatigue attributions in relation to fatigue, health, psychosocial work characteristics, and sociodemographics of employees who made a fatigue related visit to the GP only ( $n=268$ )

\begin{tabular}{|c|c|c|c|}
\hline & $\begin{array}{l}\text { Somatic attribution } \\
(41.8 \%)\end{array}$ & $\begin{array}{l}\text { Psychological } \\
\text { attribution } \\
(44.0 \%)\end{array}$ & $\begin{array}{l}\text { Don't know attribution } \\
(14.2 \%)\end{array}$ \\
\hline \multicolumn{4}{|l|}{ Fatigue } \\
\hline CIS total score ${ }^{* * *}$ & $69.9(23.8)$ & $82.0(25.11)$ & 84.3 (21.3) \\
\hline $\mathrm{CIS}$ case $* * *$ & $41.3 \%$ & $62.7 \%$ & $65.8 \%$ \\
\hline $\mathrm{CIS}$ case four months ago & $41.0 \%$ & $52.3 \%$ & $57.1 \%$ \\
\hline MBI-GS case* & $28.9 \%$ & $48.9 \%$ & $39.1 \%$ \\
\hline \multicolumn{4}{|l|}{ Somatic health problems } \\
\hline$\geqslant 1$ Chronic illness & $36.6 \%$ & $28.0 \%$ & $31.6 \%$ \\
\hline \multicolumn{4}{|l|}{ Mental health problems } \\
\hline HAD anxiety*** & $6.2(3.2)$ & $9.0(3.6)$ & $8.7(3.6)$ \\
\hline HAD depression *** & $5.1(3.8)$ & $8.2(4.4)$ & $6.6(4.1)$ \\
\hline HAD case ${ }^{* * *}$ & $32.4 \%$ & $64.3 \%$ & $59.5 \%$ \\
\hline \multicolumn{4}{|c|}{ Psychosocial work characteristics (JCQ total score on subscales) } \\
\hline Job demands & $32.8(5.8)$ & $34.2(5.5)$ & $33.6(4.9)$ \\
\hline Decision latitude & $70.3(11.6)$ & $71.9(11.1)$ & $72.2(10.7)$ \\
\hline Social support & $21.5(3.5)$ & $21.6(3.4)$ & $21.7(3.4)$ \\
\hline \multicolumn{4}{|l|}{ Sociodemographics } \\
\hline Age (years) & $41.3(8.2)$ & $41.6(7.4)$ & $40.7(9.3)$ \\
\hline Gender ( $\%$ male) & $62.2 \%$ & $68.6 \%$ & $57.9 \%$ \\
\hline Low educational level & $17.8 \%$ & $9.8 \%$ & $15.8 \%$ \\
\hline Living alone & $10.0 \%$ & $12.7 \%$ & $7.9 \%$ \\
\hline
\end{tabular}

$\mathrm{CIS}$, Checklist Individual Strength; CIS case, probable fatigue case; MBI-GS, Maslach Burnout Inventory-General Survey; MBI-GS case, probable work related fatigue case; HAD, Hospital Anxiety and Depression Scale; HAD case, probable mental health problem case; JCQ, Job Content Questionnaire. $t$ test $/ \chi^{2}$ test, ${ }^{*} p<0.05{ }^{* *} p<0.01{ }^{* * *} p<0.001$

Table 3 Cases versus non-cases with respect to fatigue, chronic illness, mental health problems, and job strain in relation to fatigue attributions of employees who made a fatigue related visit to the GP only $(n=268)$

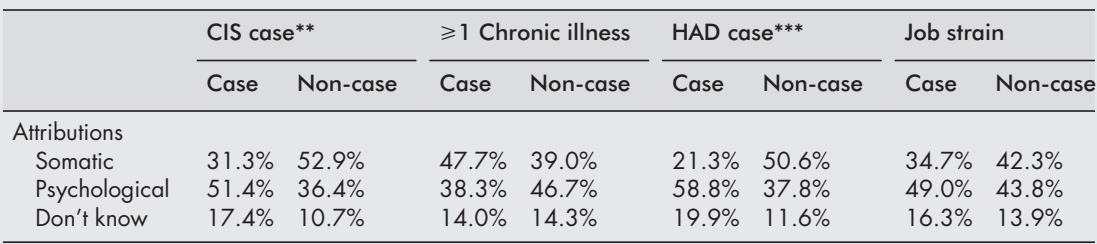

CIS, Checklist Individual Strength; CIS case, probable fatigue case; HAD, Hospital Anxiety and Depression Scale; HAD case, probable mental health problem case.

$\chi^{2}$ test, ${ }^{* *} p<0.01{ }^{* * *} p<0.001$

Being a mental health problem case turned out to be associated with how employees attribute their fatigue complaints $\left(\chi^{2}(\mathrm{df}=2)=8.99, \mathrm{p}<0.05\right)$, over and beyond being a probable fatigue case. As shown by the results in table 4, this association was only present when comparing employees with a psychological fatigue attribution to employees with a somatic attribution.

\section{Differences between visiting only the GP and only the OP}

In contrast to one of three (35.0\%) employees visiting only the GP, a minority $(3.0 \%)$ of the employees at work indicated visiting only the OP. However, when compared to employees who made a fatigue related visit to the GP only, twice as many employees made a fatigue related visit to the OP only $(29.0 \%$ versus $13.9 \%$ ). Furthermore, the vast majority (73.9\%) of those employees who made a fatigue related visit to the OP only attributed their fatigue complaints to a psychological cause, followed by $19.6 \%$ to a somatic cause, and the minority $(6.5 \%)$ reported no attribution for their fatigue complaints, while this attribution pattern was $44.0 \%, 41.8 \%$, and $14.2 \%$ for employees who made a fatigue related visit to only the GP (see table 1). Because of small sample sizes for the somatic fatigue attribution group $(\mathrm{n}=9)$ and the "don't know" fatigue attribution group $(\mathrm{n}=3)$ in employees who made a fatigue related visit to only the OP, it was not possible to test for statistical differences on the level of the employees' health and work characteristics.

Table 4 Multinomial logistic regression of cases versus non-cases with respect to fatigue, chronic illness, mental health problems, and job strain on a somatic, psychological (reference group), or no attribution of fatigue in employees who made a fatigue related visit to the GP only, adjusted for sociodemographics ( $n=268$ )

\begin{tabular}{lllll}
\hline & \multicolumn{2}{l}{ Odds ratio $(95 \% \mathrm{Cl})$} & & \\
\cline { 2 - 5 } & $\begin{array}{l}\text { Psychological versus } \\
\text { somatic attribution }\end{array}$ & $\begin{array}{l}\text { Psychological versus } \\
\text { no attribution }\end{array}$ \\
\hline Cases versus non-cases & & & & \\
CIS case & 1.66 & $(0.87$ to 3.20$)$ & 0.97 & $(0.38$ to 2.47$)$ \\
$\geqslant 1$ Chronic illness & 0.56 & $(0.29$ to 1.06$)$ & 0.76 & $(0.32$ to 1.79$)$ \\
HAD case & 2.51 & $(1.16$ to 5.42$) *$ & 0.65 & $(0.26$ to 1.62$)$ \\
Job strain & 1.46 & $(0.67$ to 3.20$)$ & 1.08 & $(0.40$ to 2.91$)$ \\
\hline
\end{tabular}

$\mathrm{CIS}$, Checklist Individual Strength; CIS case, probable fatigue case; HAD, Hospital Anxiety and Depression Scale; HAD case, probable mental health problem case.

$\chi^{2}$ test, ${ }^{*} p<0.05$. 


\section{DISCUSSION}

To our knowledge, our study was the first to examine fatigue attributions of patients in a working population. In our study population consisting of employees actively at work, a high proportion of employees have consulted their GP for fatigue as a presenting or supporting symptom in the previous six months. In these employees, not only higher levels of fatigue but also more indicators of mental health problems, and to a lesser extent of physical health problems and a negative perception of the psychosocial work environment were present. Hence, establishing that a visit is fatigue related is only moderately effective in getting more insight in the diffuse relation between fatigue and health and psychosocial work characteristics. Asking employees making a fatigue related visit about their own fatigue attributions seems to be more helpful in evaluating which health problems may be present besides fatigue itself. Especially reporting a psychological fatigue attribution was associated with the presence of not only a higher fatigue level, but also with a higher level of anxiety and/or depression as mental health problems. Furthermore, the finding that being a probable health problem case instead of being a probable fatigue case matched with reporting a psychological attribution. This finding may indicate that a psychological fatigue attribution is more likely to result from the presence of mental health problems than from the presence of fatigue itself.

Several other studies have examined fatigue attributions in patients reporting fatigue complaints to the GP. ${ }^{82} 33$ The finding that an almost equal proportion of employees who made a fatigue related visit to the GP attributed their fatigue to somatic or psychological problems supports evidence from other studies undertaken in the community, for example Ridsdale and colleagues. ${ }^{34}$ It is noteworthy that physical attributions of fatigue are more widespread in secondary and tertiary care patients than in primary care patients. ${ }^{35-37}$ This is an interesting finding, as it might indicate that the greater openness of patients to psychological as well physical interpretations for their symptoms in primary care is likely to make them more willing to participate in complex interventions in this context. Further research regarding interventions in primary care contexts is necessary to examine this possibility.

As our study comprised a working population, we were also interested in employees' perception of their work environment - that is, their psychosocial work characteristics. We found no association between fatigue attributions and psychosocial work characteristics. This is noteworthy, as a negative perception of the work environment is found to be associated with fatigue on both a cross sectional ${ }^{13}$ and a longitudinal level. ${ }^{14}$ Not finding an association between fatigue attributions and psychosocial work characteristics might have been due to comparing psychological to somatic attributions instead of comparing attributions in terms of being work related or not being work related. Alternatively, not finding an association might also indicate that employees do not take psychosocial work characteristics into account when attributing their fatigue complaints; possibly, psychosocial work characteristics are in particular taken into account by employees who are not actively at work but are absent from work.

Because of the cross sectional nature of this study and as the visit to the GP or OP could have taken place recently or a few months ago (with a maximum of six months), the results do not disentangle whether fatigue attributions influenced the decision to consult a physician, whether feedback from the physician influenced the employees' own fatigue attributions, or both. As all measures were based on self report of the employees, we also cannot rule out that common method variance may have lead to spurious associations. However, these self report measures can be considered as more relevant in this study than using objective measures, since we were interested in factors experienced by the employee in relation to a concrete action undertaken by those employees (consulting a physician). With respect to the generalisation of our findings, it should be mentioned that by selecting employees who were active at work (not on sick leave) and made a fatigue related visit to the GP or OP only, we focused on a selective and homogeneous group of employees. Our goal was to specifically examine the employees' own attributions of their fatigue complaints. By excluding those employees who were absent from work and/or consulted both the GP and OP, we tried to diminish the influence of the labelling of GPs and OPs on the employees' own fatigue attributions.

It should be noted that although a considerably higher percentage of employees visited the GP than the OP $(35.0 \%$ versus $3.0 \%$ ), a more than twice as high percentage of these employees made a fatigue related visit to the OP than to the GP $(29.0 \%$ versus $13.9 \%)$, and that a higher percentage of employees who made a fatigue related visit to only the OP instead of only the GP reported a psychological fatigue attribution $(73.0 \%$ versus $44.0 \%)$. Employees making a fatigue related visit to only the OP might report other levels of fatigue, health problems, and/or psychosocial work characteristics than those visiting only the GP, but the number of OP visitors was too small to examine this. The finding that a far smaller number of employees visited the OP than the GP also calls for further research, for example, regarding how employees active at work perceive the role of the OP when compared to the role of the GP.

In conclusion, our study indicated that paying attention to employees' own fatigue attributions in terms of somatic or psychological causes may be useful in providing the GP-and possibly also the $\mathrm{OP}$-more insight in underlying health problems in employees active at work and making a fatigue related visit, but not in underlying psychosocial work characteristics.

\section{ACKNOWLEDGEMENTS}

As a part of the Maastricht Cohort Study on Fatigue at Work, this study participates in the Netherlands concerted research action on "Fatigue at Work" and receives a grant from the Netherlands Organisation for Scientific Research (NWO grant no. 580-02.255, part I). The authors would like to thank Marcus Huibers for comments on an earlier draft of this paper.

\section{Authors' affiliations}

H Andrea, J F M Metsemakers, C P van Schayck, Department of General Practice, Maastricht University, Maastricht, Netherlands

IJ Kant, Department of Epidemiology, Maastricht University, Maastricht, Netherlands

A J H M Beurskens, Department of Epidemiology, Maastricht University; Hogeschool Zuyd, University of Professional Education, Department of Physiotherapy, Heerlen, Netherlands

\section{REFERENCES}

1 Chen MK. The epidemiology of self-perceived fatigue among adults. Prev Med 1986;15:74-81.

2 Loge JH, Ekeberg O, Kaasa S. Fatigue in the general norwegian population: normative data and associations. J Psychosom Res 1998;45:53-65.

3 Pawlikowska T, Chalder T, Hirsch SR, et al. Population based study of fatigue and psychological distress. BM 1994;308:763-6.

4 Bültmann U, Kant IJ, Kasl S, et al. Fatigue and psychological distress in the working population: psychometrics, prevalence and correlates. J Psychosom Res 2002;52:443-50.

5 Schröer CAP. De toename van arbeidsongeschiktheid wegens psychische aandoeningen [The increase of work disability due to mental disorders]. Tiidschrift voor bedrijfs- en verzekeringsgeneeskunde 1997:5: 16-23.

6 Chisholm D, Godfrey E, Ridsdale L, et al. Chronic fatigue in general practice: economic evaluation of counselling versus cognitive behaviour therapy. Br J Gen Pract 2001;51:15-18.

7 Tiesinga LJ, Dassen TWN, Halfens RJG. Fatigue: a summary of the definitions, dimensions, and indicators. Nursing Diagnosis 1996;7:51-62

8 Cathébras PJ, Robbins JM, Kirmayer $\mathrm{L}$, et al. Fatigue in primary care: prevalence, psychiatric comorbidity, illness behavior and outcome. J Gen Intern Med 1992;7:276-86.

9 Lewis G, Wessely S. The epidemiology of fatigue: more questions than answers. J Epidemiol Community Health 1992;33:191-8. 
10 Hotopf M, Mayou R, Wadsworth M, et al. Temporal relationships between physical symptoms and psychiatric disorder. Results from a national birth cohort. Br J Psychiatry 1998;173:255-61.

11 Kisely SR, Goldberg DP. Physical and psychiatric comorbidity in general practice. Br J Psychiatry 1996;169:236-42.

12 Verhaak P. Somatic disease and psychological disorder. J Psychosom Res 1997;42:261-73.

13 Bültmann U, Kant I, Schröer K, et al. The relationship between psychosocial work characteristics and fatigue and psychological distress. Int Arch Occup Environ Health 2001:75:259-66.

14 Bültmann U, Kant IJ, Van den Brandt PA, et al. Psychosocial work characteristics as risk factors for the onset of fatigue and psychological distress: prospective results from the Maastricht Cohort Study. Psychol Med 2001;32:333-45.

15 Muntaner C, Schoenbach C. Psychosocial work environment and health in U.S. metropolitan areas: a test of the demand-control and demand-control-support models. Int J Health Serv 1994;24:337-53.

16 Ridsdale L. A critical appraisal of the literature on tiredness. In: General practice; a critical reader. London: W.B. Saunders Company Ltd, 1995.

17 Buijs P, Van Amstel R, Van Dijk F. Guidance of sickness absence: cooperation of Dutch occupational physician and general practitioner. In: Caillard J-F, Westerholm P, eds. Systèmes de Sécurité sociale et d'assurance maladie: financement et implication dans la santé au travail [Social Security Systems and Health Insurance: financing and implication in occupational health]. Toulouse: Octares Editions, 1999.

18 Kant IJ, Beurskens A, Schröer C, et al. De Maastrichtse Cohort Studie naar langdurige psychische vermoeidheid in de arbeidssituatie [The Maastricht Cohort Study of prolonged Fatigue at Work]. Tijdschrijft voor bedriifs en verzekeringsgeneeskunde 2000;8:226-32.

19 Beurskens AJHM, Bültmann U, Kant IJ, et al. Fatigue among working people: validity of a questionnaire measure. Occup Environ Med 2000;57:353-7

20 Vercoulen JHMM, Swanink CMA, Fennis JFM, et al. Dimensional assessment of chronic fatigue syndrome. J Psychosom Res 1994;38:383-92.

21 Bültmann, U, De Vries M, Beurskens AJHM, et al. Measurement of prolonged fatigue in the working population: determination of a cutoff point for the Checklist Individual Strength. J Occup Health Psychol 2000;5:411-16.

22 Maslach C, Jackson SE. Maslach Burnout Inventory manual. Palo Alto, CA: Consulting Psychologists Press, 1986
23 Schaufeli WB Van Dierendonk D. UBOS, Utrechtse Burnout Schaal, Handleiding [MBI-GS, Maslach Burnout Inventory-General Survey, Dutch Manual]. Lisse: Swets Test Publishers, 2000.

24 Zigmond AS, Snaith RP. The Hospital Anxiety and Depression Scale. Acta Psychiatr Scand 1983;67:361-70.

25 Wilkinson MJB, Barczak P. Psychiatric screening in general practice: comparison of the general health questionnaire and the hospital anxiety depression scale. J R Coll Gen Pract 1988;38:311-13.

26 Dowell AC, Biran LA. Problems in using the hospital anxiety and depression scales for screening patients in general practice. $\mathrm{Br} J \mathrm{Gen}$ Pract 1990;40:27-8.

27 Houtman I. Reliability and validity of the Dutch version of the Karasek Job Content Questionnaire. NIOSH/APA conference on stress, work and health. Washington, DC: APA, 1995.

28 Karasek R. The job content questionnaire and users's guide. Los Angeles, CA: University of South California, Department of Industrial and Systems Engineering, 1985.

29 Karasek RA. Job demands, job decision latitude, and mental strain: implications for job redesign. Adm Sci Q 1979;24:285-31 1 .

30 Karasek R, Theorell T. Healthy work: stress, productivity and the reconstruction of working life. New York: Basic Books, 1990.

31 Toothaker L. Multiple comparison procedures. Sage University paper series on quantitative applications in the social sciences, 07-089. Newbury Park, CA: Sage, 1993.

32 Kirk J, Douglass R, Nelson E, et al. Chief complaint of fatigue: a prospective study. J Fam Pract 1990;30:33-41.

33 Ridsdale L, Mandalia S, Evans A, et al. Tiredness as a ticket of entry-the role of patients' beliefs and psychological symptoms in explaining frequent attendence. Scand J Prim Health Care 1999; 17:72-4.

34 Ridsdale L, Godfrey E, Chalder T, et al. Chronic fatigue in general practice: is counselling as good as cognitive behaviour therapy? A UK randomised trial. Br J Gen Pract 2001;51:19-24.

35 Deale, A, Chalder T, Wessely S. Illness beliefs and treatment outcome in chronic fatigue syndrome. J Psychosom Res 1998;45:77-83.

36 Dendy C, Cooper M, Sharpe M. Interpretation of symptoms in chronic fatigue syndrome. Behav Res Ther 2001;39:1369-80.

37 Sharpe M, Hawton KE, Simkin S, et al. Cognitive behaviour therapy for the chronic fatigue syndrome: a randomized controlled trial. BM 1996:312:22-6. 